\title{
CONTINUED FRACTIONS, THE PERTURBATION METHOD AND EXACT SOLUTIONS TO NONLINEAR EVOLUTION EQUATIONS
}

\author{
A. I. Zemlyanukhin, A. V. Bochkarev \\ Yuri Gagarin State Technical University of Saratov \\ Politekhnicheskaya 77, Saratov, 410008, Russia \\ E-mail: zemlyanukhinai@sstu.ru
}

\begin{abstract}
A new method is proposed in which constructing exact solutions to nonlinear evolution equations is based on successive applying the perturbation method and apparatus of the continued fractions. It is shown that exact solitary-wave solutions arise in the limiting case as the sum of geometric series of the perturbation method based on the linearized problem. It is demonstrated that the continued fraction corresponding to the perturbation series, terminates to a convergent giving an expression for the desired exact soliton-like solution. The order of the convergent is established to be not less than twice the pole order of the original equation's solution. The effectiveness of the method is demonstrated on the solution of integrable 5th order equation of the Korteweg-de Vries family, 3rd order equation with 5 arbitrary constants, the Calogero-Degasperis-Fokas equation and the non-integrable Kuramoto-Sivashinsky equation. The analysis showed that in the case of integrable equations the continued fraction corresponding to the perturbation series terminates unconditionally, that is, the series is geometric or becomes so after regrouping the terms. For non-integrable equations the requirement of termination of the continued fraction that is equivalent to the geometricity of the perturbation series leads to the conditions on the original equation coefficients, which are necessary for the existence of exact soliton-like solutions. The advantages of the method, which can be easily implemented using any of the computer mathematics systems, include the ability to work with equations, the solution of which has a pole of zero, fractional or higher natural order.
\end{abstract}

Keywords: Continued fractions, perturbation method, exact solutions, nonlinear evolution equations.

DOI: $10.18500 / 0869-6632-2016-24-4-71-85$

Paper reference: Zemlyanukhin A.I., Bochkarev A.V. Continued fractions, the perturbation method and exact solutions to nonlinear evolution equations // Izvestiya VUZ. Applied Nonlinear Dynamics, 2016. Vol. 24. N4. P. 71-85.

(C) А.И. Землянухин, А.В. Бочкарёв

Изв. вузов «ПНД», т. 24, № 4, 2016 


\section{Introduction}

Forty-five years ago R. Hirota published a paper [1] presenting a direct bilinear method to construct $\mathrm{N}$-soliton solutions and Backlund transformations for integrable equations. The basic idea was to replace the dependent variable to bring the original equation to bilinear form, for which a perturbation series is terminated at soliton solutions. The solutions in this case are represented by Pade approximants [2] of a special kind. Hirota noted that the use of Pade summation technique to the perturbation series for the original equation is possible, but not advisable because of too slow convergence or even divergence of such a series [1]. Furthermore,it is known [3] that the soliton, as a fundamentally nonlinear formation cannot be obtained in any finite order of the perturbation method based on the solution to the linearized problem.

The aim of this article is to expand understanding of the possibilities of direct perturbation method for integrable and nonintegrable equations and to offer effective techniques to build their exact soliton-like solutions. For summation of the perturbation series we will apply the techniques of continuous fractions [4], which is closely connected with Pade approximants, but historically arisen much earlier. In the framework of this approach the special properties of the series [5] that allow to find exact solutions to nonlinear evolution equations will be identified.

Following [1], we first consider the Korteweg - de Vries (KdV) equation

$$
u_{t}+6 u u_{x}+u_{x x x}=0 .
$$

For the KdV equation (1), we seek a solution asymptotically vanishing at infinity. Let us denote $u=w_{x}$, integrate the equation (1) for $x$ and choose the constant of integration equal to zero:

$$
w_{t}+3 w_{x}^{2}+w_{x x x}=0 .
$$

Substituting the expansion

$$
w=\sum_{n=t}^{\infty} \varepsilon^{n} w_{n}(x, t)
$$

into equation (2), collect terms with the same degrees of $\varepsilon$. We obtain the infinite system of equations for determining the functions $w_{n}(x, t)$ :

$$
\begin{array}{ll}
\varepsilon^{1}: & w_{1 t}+w_{1, x x x}=0 \\
\varepsilon^{2}: & w_{2 t}+w_{2, x x x}=-3 w_{1 x}^{2} \\
\varepsilon^{3}: & w_{3 t}+w_{3, x x x}=-6 w_{1 x} w_{2 x} \\
\varepsilon^{4}: & w_{4 t}+w_{4, x x x}=-6 w_{1 x} w_{3 x}-3 w_{2 x}^{2},
\end{array}
$$

The first equation of (4) has a particular solution $w_{1}=\exp (k x-\omega t)$ under the condition $\omega=k^{3}$, which is the dispersion relation of the linearized problem. Each of the subsequent equations of the system (4) has a solution of the form $w_{n}=K_{n}(\exp (k x-\omega t))^{n}$, 
where $n$ is the number of the equation and $K_{n}$ is a constant. Sequentially calculating the constants $K_{2}, K_{3}, \ldots$ and denoting

$$
z=\varepsilon \exp (k x-\omega t),
$$

the expression (3) can be written in the form of the power series

$$
w=z-\frac{z^{2}}{2 k}+\frac{z^{3}}{4 k^{2}}-\frac{z^{4}}{8 k^{3}}+\frac{z^{5}}{16 k^{4}}-\frac{z^{6}}{32 k^{5}}+\ldots
$$

It is seen that the series (6) is geometric with the first term $\mathrm{z}$ and common factor $-z /(2 k)$.

Under condition $|z /(2 k)|<1$ the series (6) converges and has the sum

$$
w=\frac{z}{1+\frac{1}{2 k} z}=\frac{\varepsilon \exp \left(k x-k^{3} t\right)}{1+\frac{\varepsilon}{2 k} \exp \left(k x-k^{3} t\right)} .
$$

The last expression is an exact solution to (2) for all values of the constants $\varepsilon$ and $k$. Differentiating (7) by $x$, we obtain one-soliton solution of the KdV equation (1):

$$
u=\frac{4 k^{3} \varepsilon \exp \left(k x-k^{3} t\right)}{\left[2 k+\varepsilon \exp \left(k x-k^{3} t\right)\right]^{2}} .
$$

Note that introducing the notation $F=1+\exp \left[k x-k^{3} t+\ln (\varepsilon /(2 k))\right]$, the solution (7) can be represented in the form $w=2(\ln F)_{x}$. Then $u=w_{x}=2(\ln F)_{x x}$, which coincides with the Hirota formula for the $\mathrm{N}$-soliton solution or transformation that converts the $\mathrm{KdV}$ equation to the bilinear form.

At this stage, most important that solitary-wave solution (7) occurs not in some finite order of the perturbation method, but arises in the limit as the exact sum of the geometric series (6).

The property of geometricity of the perturbation series was used previously in $[6,7]$ to construct the so-called padeons, in [8] to suggest the formal linearization method. However, the study of the universality of this property for integrable equations and the possibility of its effective use in non-integrable cases has not previously been conducted.

The structure of the perturbation series for the majority of integrable equations is much more complicated than for the $\mathrm{KdV}$ equation. In such cases to identify the geometricity of the series it is convenient to use the apparatus of continued fractions.

\section{Continued fractions and power series}

Any power series with nonzero coefficients $a_{n}$

$$
z+\sum_{n=2}^{\infty} a_{n} z^{n}
$$

can be put into correspondence with continued fraction [9]

$$
\frac{z}{1+\frac{b_{2} z}{1+\frac{b_{3} z}{1+\frac{b_{4} z}{1+\ldots}}}}
$$

(c) А.И. Землянухин, А.В. Бочкарёв

Изв. вузов «ПНД», т. 24, № 4, 2016 
whose coefficients $b_{n}$ are calculated by the formulas

$$
\begin{aligned}
& b_{2}=-a_{2}, \\
& b_{3}=\frac{a_{2}^{2}-a_{3}}{a_{2}}, \\
& b_{4}=\frac{a_{2} a_{4}-a_{3}^{2}}{a_{2}\left(a_{2}^{2}-a_{3}\right)}, \\
& b_{5}=\frac{\left(a_{2}^{2} a_{5}-2 a_{2} a_{3} a_{4}+a_{3}^{2}-a_{3} a_{5}+a_{4}^{2}\right)}{\left(a_{2}^{2}-a_{3}\right)\left(a_{2} a_{4}-a_{3}^{2}\right)},
\end{aligned}
$$

The first $n$ levels of the fraction (9) form its $n$-th convergent $P_{n} / Q_{n}$ :

$$
\begin{aligned}
& \frac{P_{1}}{Q_{1}}=z \\
& \frac{P_{2}}{Q_{2}}=\frac{z}{1+b_{2} z}, \\
& \frac{P_{3}}{Q_{3}}=\frac{z}{1+\frac{b_{2} z}{1+b_{3} z}}=\frac{z+b_{3} z^{2}}{1+\left(b_{2}+b_{3}\right) z}, \\
& \frac{P_{4}}{Q_{4}}=\frac{z}{1+\frac{b_{2} z}{1+\frac{b_{3} z}{1+b_{4} z}}}=\frac{z+\left(b_{3}+b_{4}\right) z^{2}}{1+\left(b_{2}+b_{3}+b_{4}\right) z+\left(b_{2} b_{4}\right) z^{2}}
\end{aligned}
$$

Expressions (10) can be obtained by equating the convergents $P_{n} / Q_{n}$ to corresponding partial sums of the series (8).

The convergents (11) of the series (8) form a stepped sequence of Pade approximants $[\mathrm{A} / \mathrm{B}]$ of this series $[10]$

$$
\frac{P_{n}}{Q_{n}}=\left\{\begin{array}{l}
{\left[\frac{n}{2} / \frac{n}{2}\right], \quad n-\text { even },} \\
{\left[\frac{n+1}{2} / \frac{n-1}{2}\right], \quad n-\text { odd } .}
\end{array}\right.
$$

Continued fraction (9) is truncated and becomes its $N$-th convergent, if for any $n>N$,

$$
\frac{P_{n+1}}{Q_{n+1}}=\frac{P_{n}}{Q_{n}} .
$$

The difference between two consecutive convergents satisfies the condition [11]

$$
\frac{P_{n+1}}{Q_{n+1}}-\frac{P_{n}}{Q_{n}}=\frac{(-1)^{n} z^{n+1} b_{2} b_{3} \cdot \ldots \cdot b_{n+1}}{Q_{n+1} Q_{n}} .
$$


The equation (12) gives a sufficient condition for continued fraction to be truncated: for any $n>N$ equality

$$
B_{n}=b_{2} b_{3} \cdot \ldots \cdot b_{n+1}=0
$$

is true.

Truncation of the continued fraction corresponding to power series means that the series is geometric perhaps after rearrangement of its terms. In the examples considered below the power series is a perturbation series of the evolution equation to be solved. The establishment of geometricity of the series is equivalent to finding the exact solitarywave solution.

\section{Equation of the KDV family}

Consider the 5th order KdV-type evolution equation [12]

$$
u_{t}+u_{x x x x x}+10 u u_{x x x}+20 u_{x} u_{x x}+30 u^{2} u_{x}=0 .
$$

In accordance with the direct perturbation method the solution to (14) can be found in the form of a functional series in powers of a parameter $\varepsilon$ :

$$
u=\sum_{n=1}^{\infty} \varepsilon^{n} u_{n}(x, t)
$$

Substituting (15) into (14) and collecting the terms with identical power of $\varepsilon$, e get the system

$$
\begin{aligned}
\varepsilon^{1}: u_{1 t}+u_{1 x x x x x}= & 0, \\
\varepsilon^{2}: u_{2 t}+u_{2 x x x x x}= & -10 u_{1} u_{1 x x x}-20 u_{1 x} u_{1 x x}, \\
\varepsilon^{3}: u_{3 t}+u_{3 x x x x x}= & -10\left(u_{1} u_{2 x x x}+u_{2} u_{1 x x x}\right)-20\left(u_{1 x} u_{2 x}\right)_{x}- \\
& -30 u_{1}^{2} u_{1 x}, \\
\varepsilon^{4}: u_{4 t}+u_{4 x x x x x}= & -10\left(u_{1} u_{3 x x x}+u_{2} u_{2 x x x}+u_{3} u_{1 x x x}\right)- \\
& -20\left(\left(u_{1 x} u_{3 x}\right)_{x}+u_{2 x} u_{2 x x}\right)- \\
& -30 u_{1}\left(u_{1} u_{2 x}+2 u_{2} u_{1 x}\right),
\end{aligned}
$$

The first equation of (16) has a solution $u_{1}=\exp (k x-\omega t)$ under the condition

$$
\omega=k^{5} \text {. }
$$

Finding the solutions to the following equations of (16) in the form $u_{n}=K_{n}(\exp (k x-\omega t))^{n}$, define constants $K_{n}$. Introducing the notation (5), expression (15) can be given the form of a power series

$$
u=z-\frac{z^{2}}{k^{2}}+\frac{3}{4} \frac{z^{3}}{k^{4}}-\frac{1}{2} \frac{z^{4}}{k^{6}}+\frac{5}{16} \frac{z^{5}}{k^{8}}-\frac{3}{16} \frac{z^{6}}{k^{10}}+\frac{7}{64} \frac{z^{7}}{k^{12}}-\frac{1}{16} \frac{z^{8}}{k^{14}}+\ldots
$$


Now we construct the continued fraction corresponding to the series (18). By calculating the values $b_{n}$ using formulas (10), we write expressions for sequence of $B_{n}(13)$ :

$$
B_{1}=\frac{1}{k^{2}}, \quad B_{2}=-\frac{1}{4 k^{4}}, \quad B_{3}=-\frac{1}{16 k^{6}}, \quad B_{4}=0, \quad B_{5}=0, \quad \cdots
$$

Starting with $n=4$, all values of $B_{n}$ turn to zero, therefore, continued fraction corresponding to the series (18) terminates and degenerates into 4th convergent (Pade approximant [2/2])

$$
\frac{P_{4}}{Q_{4}}=[2 / 2]=\frac{z}{1+\frac{b_{2} z}{1+\frac{b_{3} z}{1+b_{4} z}}}=\frac{4 k^{4} z}{\left(2 k^{2}+z\right)^{2}} .
$$

Represent the fraction (19) as the sum of geometric series

$$
\frac{P_{4}}{Q_{4}}=\frac{z}{1-\left(-\frac{z}{k^{2}}-\frac{z^{2}}{4 k^{4}}\right)}=z \sum_{n=0}^{\infty}\left(-\frac{z}{k^{2}}-\frac{z^{2}}{4 k^{4}}\right) .
$$

By grouping the terms of the last expression in powers of $z$, we will receive the series (18). In other words, the use of continued fraction allows to rearrange the perturbation series for equation (14) to geometric one (20) in such a way that the sum of the series coincides with the corresponding convergent and is an exact solution to the original equation. In fact after the substitutions (5) and (17) the fraction (19) takes the form

$$
\frac{4 k^{4} \varepsilon \exp \left(k x-k^{5} t\right)}{\left[2 k^{2}+\varepsilon \exp \left(k x-k^{5} t\right)\right]^{2}}
$$

and becomes the exact solution to the equation (14).

Note that there is a relationship between the pole order of integrable equation's solution and the order of convergent, which truncates the continued fraction for the perturbation series. In this case, equation (14), as well as any equation of the $\mathrm{KdV}$ hierarchy, has a solution with a pole of second order $(p=2)$. From (19) it is seen that corresponding convergent has the order of $2 p$, that is, the Pade approximants stop to change starting with order $[p / p]$.

\section{Integrable equation of the 3rd order}

Equation

$$
u_{t}=u_{x x x}-\frac{3}{8} \frac{\left(Q+u_{x}^{2}\right)_{x}^{2}}{u_{x}\left(Q+u_{x}^{2}\right)}+\frac{1}{2} Q^{\prime \prime} u_{x}
$$

where $Q=c_{0}+c_{1} u+c_{2} u^{2}+c_{3} u^{3}+c_{4} u^{4}$ is an arbitrary polynomial, is the second canonical form of the equation $K_{6}$ from the encyclopedia of integrable systems [13].

Find the solution to equation (21) in the manner described in section 3. After multiplying (21) term by term by $u_{x}\left(Q+u_{x}^{2}\right)$, we substitute (15) in (21) and group 
the obtained expression in powers of $\varepsilon$. Assuming $c_{0} \neq 0$, we arrive at a system of equations

$$
\begin{aligned}
& \begin{aligned}
\varepsilon^{1}: \quad 0=0 & \\
\varepsilon^{2}: \quad c_{0} u_{1 t}+ & \left(\frac{3}{8} c_{1}^{2}-c_{0} c_{2}\right) u_{1 x}-c_{0} u_{1 x x x}=0 \\
\varepsilon^{3}: \quad c_{0} u_{2 t}+ & \left(\frac{3}{8} c_{1}^{2}-c_{0} c_{2}\right) u_{2 x}-c_{0} u_{2 x x x}=\frac{3}{8}\left(8 c_{0} c_{3}-4_{c} 1 c_{2}+\frac{c_{1}^{3}}{c_{0}}\right) u_{1} u_{1 x}- \\
-\frac{3 c_{1}}{2} u_{1 x} u_{1 x x}, & \\
\varepsilon^{4}: \quad c_{0} u_{3 t}+ & \left(\frac{3}{8} c_{1}^{2}-c_{0} c_{2}\right) u_{3 x}-c_{0} u_{3 x x x}=\frac{3}{8}\left(8 c_{0} c_{3}-4 c_{1} c_{2}+\frac{c_{1}^{3}}{c_{0}}\right)\left(u_{1} u_{2}\right)_{x}- \\
& \quad-\frac{3 c_{1}}{2}\left(u_{1 x} u_{2 x}\right)_{x}-\frac{3}{2} u_{1 x} u_{1 x x}^{2}-\frac{3}{2}\left(2 c_{2}-\frac{c_{1}^{2}}{c_{0}}\right) u_{1} u_{1 x} u_{1 x x}+\frac{3 c_{1}^{2}}{8 c_{0}} u_{1 x}^{3}+ \\
& +\frac{3}{8 c_{0}^{2}}\left(16 c_{0}^{3} c_{4}-6 c_{0}^{2} c_{1} c_{3}-4 c_{0}^{2} c_{2}^{2}+5 c_{0} c_{1}^{2} c_{2}-c_{1}^{4}\right) u_{1}^{2} u_{1 x},
\end{aligned}
\end{aligned}
$$

The equation at order $\varepsilon^{2}$ has the particular solution $u_{1}=\exp (k x-\omega t)$, under condition

$$
\omega=-k^{3}+k\left(\frac{3 c_{1}^{2}}{8 c_{0}}-c_{2}\right) .
$$

Sequentially solving the following equations (22), for series (15) we have

$$
\begin{aligned}
u= & z-\frac{z^{2}}{16 k^{2} c_{0}^{2}}\left[8 c_{0}^{2} c_{3}-4 c_{1}\left(k^{2}+c_{2}\right) c_{0}+c_{1}^{3}\right]+ \\
+ & \frac{z^{3}}{1024 k^{4} c_{0}^{4}}\left[64\left(3 c_{3}^{2}-4 c_{4} k^{2}\right)+64\left(k^{6}+2 c_{2} k^{4}-3 c_{1} c_{3} k^{2}+c_{2}^{2} k^{2}-\right.\right. \\
& \left.-3 c_{1} c_{2} c_{3}\right) c_{0}^{3}+16 c_{1}^{2}\left(k^{4}+4 c_{2} k^{2}+3 c_{1} c_{3}+3 c_{2}^{2}\right) c_{0}^{2}- \\
& \left.-4 c_{1}^{4}\left(5 k^{2}+6 c_{2}\right) c_{0}+3 c_{1}^{6}\right]-\ldots,
\end{aligned}
$$

where $z$ is defined by equality (5). Computing the coefficients $b_{n}$ of the continued fraction for the series (24) by formulas (10), we obtain that members of the sequence $B_{1}, B_{2}, \ldots$ (13) turn to zero starting with $n=4$. Consequently, the continued fraction terminates, the series (24) is geometric and its sum coincides with the 4th order convergent (Pade approximant [2/2]):

$$
\begin{aligned}
\frac{P_{4}}{Q_{4}}= & {[2 / 2]=1024 c_{0}^{4} k^{4} z /\left[1024 c_{0}^{4} k^{4}+\right.} \\
& +64 c_{0}^{2} k^{2}\left(8 c_{0}^{2} c_{3}-4 c_{1}\left(k^{2}+c_{2}\right) c_{0}+c_{1}^{3}\right) z+ \\
& +\left(64\left(4 c_{4} k^{2}+c_{3}^{2}\right) c_{0}^{4}-64\left(k^{6}+2 c_{2} k^{4}+c_{1} c_{3} k^{2}+c_{2}^{2} k^{2}+c_{1} c_{2} c_{3}\right) c_{0}^{3}+\right. \\
& \left.\left.\left.+16 c_{1}^{2}\left(3 k^{4}+4 c_{2} k^{2}+c_{1} c_{3}+c_{2}^{2}\right) c_{0}^{2}-4 c_{1}^{4}\left(3 k^{2}+2 c_{2}\right) c_{0}+c_{1}^{6}\right) z^{2}\right)\right] .
\end{aligned}
$$

Taking into account (23) and (5), fraction (25) gives the exact solution to the equation (21). 


\section{Generalized Calogero-Degasperis-Fokas (CDF) equation}

The CDF equation containing two arbitrary coefficients $\alpha$ and $\beta$

$$
u_{t}+\frac{1}{4} u_{x x x}-\frac{3}{4} \frac{u_{x} u_{x x}}{u}+\frac{3}{8} \frac{u_{x}^{3}}{u^{2}}+\frac{3}{8} u_{x}\left(\alpha u+\frac{\beta}{u}\right)^{2}=0,
$$

is integrable [14]. Above we have obtained the exact solitary-wave solutions to integrable equations: KdV-type (14) and $K_{6}$ (21). A perturbation series for each of them were definitely geometric, moreover in the case of the equation (21) geometricity of the series observed at arbitrary values of the coefficients $c_{0}, \ldots, c_{4}$.

The change in numerical multipliers of the equation may lead to its non-integrability. Consider a generalization of the CDF equation, in which one of the numeric multipliers is replaced by an arbitrary coefficient $\gamma$ :

$$
u_{t}+\gamma u_{x x x}-\frac{3}{4} \frac{u_{x} u_{x x}}{u}+\frac{3}{8} \frac{u_{x}^{3}}{u^{2}}+\frac{3}{8} u_{x}\left(\alpha u+\frac{\beta}{u}\right)^{2}=0 .
$$

Obviously, an arbitrary constant is a solution to the equation (27). Denoting this constant as $E$, we seek solitary-wave solution to this equation in the neighborhood of $E$ in the form of sum

$$
u=E+\sum_{n=1}^{\infty} \varepsilon^{n} u_{n}(x, t) .
$$

After multiplying (27) term by term by $u^{2}$, we substitute (28) in (27) and group the obtained expression in powers of $\varepsilon$ :

$$
\begin{aligned}
\varepsilon^{1}: & u_{1 t}+\gamma u_{1 x x x}+\frac{3}{8 E^{2}}\left(E^{2} \alpha+\beta\right)^{2} u_{1 x}=0, \\
\varepsilon^{2}: & u_{2 t}+\gamma u_{2 x x x}+\frac{3}{8 E^{2}}\left(E^{2} \alpha+\beta\right)^{2} u_{2 x}=\frac{3}{4 E} u_{1 x} u_{1 x x}-\frac{3\left(E^{4} \alpha^{2}-\beta^{2}\right)}{4 E^{3}} u_{1} u_{1 x}, \\
\varepsilon^{3}: \quad u_{3 t}+\gamma u_{3 x x x}+\frac{3}{8 E^{2}}\left(E^{2} \alpha+\beta\right)^{2} u_{3 x}=\frac{3}{4 E}\left(u_{1 x} u_{2 x}\right)_{x}- & \\
& -\frac{3\left(E^{4} \alpha^{2}-\beta^{2}\right)}{4 E^{3}}\left(u_{1} u_{2}\right)_{x}-\frac{3}{8 E^{2}} u_{1 x}^{3}-\frac{3}{4 E^{2}} u_{1} u_{1 x} u_{1 x x}-\frac{3\left(E^{4} \alpha^{2}+3 \beta^{2}\right)}{8 E^{4}} u_{1}^{2} u_{1 x},
\end{aligned}
$$

The first equation of (29) has the particular solution $u_{1}=\exp (k x-\omega t)$ under condition

$$
\omega=\frac{k}{8 E^{2}}\left[E^{2}\left(3 E^{2} \alpha^{2}+6 \alpha \beta+8 \gamma k^{2}\right)+3 \beta^{2}\right] .
$$

Sequentially solving the following equations (29), after the introduction of the notation (5) for the series of (28) we get

$$
\begin{aligned}
\sum_{n=1}^{\infty} \varepsilon^{n} u_{n}(x, t)= & z-\frac{z^{2}}{8 E^{3} \gamma k^{2}}\left(E^{4} \alpha^{2}-E^{2} k^{2}-\beta^{2}\right)+ \\
+\frac{z^{3}}{256 E^{6} \gamma^{2} k^{4}} & \left(3 E^{8} \alpha^{4}-E^{6} \alpha^{2} k^{2}(4 \gamma+9)+6 E^{4} k^{4}(1-2 \gamma)-\right. \\
& \left.\quad-6 E^{4} \alpha^{2} \beta^{2}+3 E^{2} \beta^{2} k^{2}(3-4 \gamma)+3 \beta^{4}\right)-\ldots
\end{aligned}
$$


Identifying the perturbation series (30) with the series (8), we calculate the coefficients $b_{n}$ of the corresponding continued fraction by formulas (10) and write the expressions for the sequence of $B_{n}(13)$ :

$$
\begin{aligned}
B_{1}=\frac{E^{4} \alpha^{2}-E^{2} k^{2}-\beta^{2}}{8 E^{3} \gamma k^{2}} & , \\
B_{2}=\frac{1}{256 E^{6} \gamma^{2} k^{4}}\left(E^{8} \alpha^{4}\right. & +E^{6} \alpha^{2} k^{2}(4 \gamma+1)+2 E^{4} k^{4}(6 \gamma-1)- \\
& \left.-2 E^{4} \alpha^{2} \beta^{2}+E^{2} \beta^{2} k^{2}(12 \gamma-1)+\beta^{4}\right),
\end{aligned}
$$

Other expressions are too bulky to be presented. All members of the sequence $B_{n}$, beginning with $B_{4}$, contain two common multipliers:

$$
(4 \gamma-1)\left(3 E^{4} \alpha^{2}+16 E^{2} \gamma k^{2}-3 E^{2} k^{2}+16 \beta^{2} \gamma-3 \beta^{2}\right) .
$$

Thus, the continued fraction is terminated in two cases:

$$
\gamma=\frac{1}{4}
$$

or

$$
\gamma=\frac{3}{16}\left(1-\frac{E^{4} \alpha^{2}}{E^{2} k^{2}-\beta^{2}}\right)
$$

The first case corresponds to the original integrable CDF equation (26). The series (30) is geometric and its sum equals to the 4 th order convergent

$$
\begin{array}{r}
\frac{P_{4}}{Q_{4}}=[2 / 2]=16 k^{4} E^{6} z /\left(\left[\left(E^{2} \alpha-\beta\right)^{2}+E^{2} k^{2}\right)\right]\left[\left(E^{2} \alpha+\beta\right)^{2}+E^{2} k^{2}\right] z^{2}+ \\
\left.+8 E^{3} k^{2}\left(E^{4} \alpha^{2}-E^{2} k^{2}-\beta^{2}\right) z+16 E^{6} k^{4}\right) .
\end{array}
$$

The second case establishes a definite relationship between the coefficients of the original equation and the parameters of sought solution for which the sum of the series (30) is defined as

$$
\begin{array}{r}
\frac{P_{4}}{Q_{4}}=[2 / 2]=36 k^{4} E^{6} z\left[\left(E^{2} k^{2}+\beta^{2}\right)\left(E^{2} k^{2}+4 \beta^{2}\right) z^{2}-\right. \\
\left.-24 E^{3} k^{2}\left(E^{2} k^{2}+\beta^{2}\right) z+36 E^{6} k^{4}\right] .
\end{array}
$$

To determine the exact solution to the equation (27) it is necessary to replace $z$ in the above fractions $P_{4} / Q_{4}$ by the expression (5), in which we do accept

$$
\omega=\frac{k}{8}\left(3 E^{2} \alpha^{2}+6 \alpha \beta+2 k^{2}+\frac{3 \beta^{2}}{E^{2}}\right)
$$

in the case of (32) and

$$
\omega=\frac{3 k}{16\left(E^{2} k^{2}+\beta^{2}\right)}\left[E^{2}\left(E^{2} \alpha^{2} k^{2}+2 \alpha^{2} \beta^{2}+4 \alpha \beta k^{2}+k^{4}\right)+\beta^{2}\left(4 \alpha \beta+3 k^{2}\right)+\frac{2 \beta^{4}}{E^{2}}\right]
$$


in the case of (33). In both cases, in accordance with (28) the exact solution has the form of $u=E+P_{4} / Q_{4}$.

Note that the solution (32) at $\alpha \neq 0$ has the pole of the 1 st order. At $\alpha=0$ there is a full square in the denominator of (32)

$$
\frac{P_{4}}{Q_{4}}=\frac{16 k^{4} E^{6} z}{\left[4 E^{3} k^{2}-\left(E^{2} k^{2}+\beta^{2}\right) z\right]^{2}}
$$

and the solution has a pole of the second order. This conclusion is consistent with the results of the pole order determination for solutions to the equation (27) using the dominant terms analysis [15]. In fact, this equation written in a variable of a traveling wave $\xi=k x-\omega t$ under the condition (31) takes the form

$$
\frac{2}{3} u_{\xi \xi \xi}-2 \frac{u_{\xi} u_{\xi \xi}}{u}+\frac{u_{\xi}^{3}}{u^{2}}+\frac{1}{k^{3}}\left(k \alpha^{2} u^{2}+2 k \alpha \beta-\frac{8 \omega}{3}+\frac{k \beta^{2}}{u^{2}}\right) u_{\xi}=0 .
$$

Replacing $u$ in (34) by a power function $p \xi^{-q}$ with constants $p$ and $q$, for the left part (34) we get

$$
k^{3} p^{2}\left(q^{2}-4\right) \xi^{-q-3}-3 \alpha^{2} k p^{4} \xi^{-3 q-1}+2 p^{2}(4 \omega-3 \alpha \beta k) \xi^{-q-1}-3 \beta^{2} k \xi^{q-1} .
$$

The first two terms of (35) have the minimum values of degree, they are dominant. Equating their degrees in accordance with the Kruskal's compensation principle [16], we find $q=1$, that is, the solution has a pole of the 1 st order.

When $\alpha=0$ the expression (35) simplifies to

$$
k^{3} p^{2}\left(q^{2}-4\right) \xi^{-q-3}+8 p^{2} \omega \xi^{-q-1}-3 \beta^{2} k \xi^{q-1} .
$$

The first term is the only dominant. Equating to zero the coefficient in front of him gives $q=2$, therefore, the decision in this case has a pole of the 2 nd order.

Thus, between the pole order $q$ of solution to the equation and the order $r$ of the convergent $P_{r} / Q_{r}$ giving the solution of this equation, there is a link:

$$
r \geq 2 q
$$

\section{Kuramoto-Sivashinsky (KS) equation}

Finding the solution to the non-integrable KS equation [17]

$$
u_{t}+u u_{x}+u_{x x}+\alpha u_{x x x}+\beta u_{x x x x}=0
$$

in the form of (15), after grouping by powers of $\varepsilon$ we have the following system of equations

$$
\begin{array}{ll}
\varepsilon^{1}: & u_{1 t}+u_{1 x x}+\alpha u_{1 x x x}+\beta u_{1 x x x x}=0, \\
\varepsilon^{2}: & u_{2 t}+u_{2 x x}+\alpha u_{2 x x x}+\beta u_{2 x x x x}=-u_{1} u_{1 x}, \\
\varepsilon^{3}: & u_{3 t}+u_{3 x x}+\alpha u_{3 x x x}+\beta u_{3 x x x x}=-\left(u_{1} u_{2}\right)_{x}, \\
\varepsilon^{4}: & u_{4 t}+u_{4 x x}+\alpha u_{4 x x x}+\beta u_{4 x x x x}=-\left(u_{1} u_{3}\right)_{x}-u_{2} u_{2 x},
\end{array}
$$


The first equation of the system (38) has a particular solution $u_{1}=\exp (k x-\omega t)$ under the condition

$$
\omega=\beta k^{4}+\alpha k^{3}+k^{2} .
$$

Sequentially solving the following equations (38), after the introduction of the notation (5) for a series (15) we get

$$
\begin{aligned}
u= & z-\frac{z^{2}}{2 k\left(7 \beta k^{2}+3 \alpha k+1\right)}+ \\
& +\frac{z^{3}}{3 k^{2}\left(13 \beta k^{2}+4 \alpha k+1\right)\left(7 \beta k^{2}+3 \alpha k+1\right)}- \\
& -\frac{\left(27 \beta k^{2}+10 \alpha k+3\right) z^{4}}{24 k^{3}\left(21 \beta k^{2}+5 \alpha k+1\right)\left(13 \beta k^{2}+4 \alpha k+1\right)\left(7 \beta k^{2}+3 \alpha k+1\right)^{2}}+\ldots
\end{aligned}
$$

The analysis of dominant terms of (37) shows that the expression (40) corresponds to a function with a pole of the 3rd order. According to the inequality (36), the exact solution of equation (37) is a convergent of the order not lower than $P_{6} / Q_{6}$ or diagonal Pade approximant at least [3/3] order. The above noted that the corresponding expressions are too bulky and difficult to operate even with the use of modern systems of symbolic mathematics. To simplify the calculation one can use appropriate transformation of the perturbation series (40). Let's use the fact that the cube root of the power series (40) corresponds to a function with a pole of the 1st order. To extract the cube root of (40), consider the equation $u=z^{-2} v^{3}$, where

$$
v=z+\sum_{n=2}^{\infty} c_{n} z^{n},
$$

and equate coefficients on both sides of this equation with equal powers of $z$. Solving the resulting equalities with respect to $c_{n}$, we find

$$
\begin{aligned}
v= & z-\frac{z^{2}}{6 k\left(7 \beta k^{2}+3 \alpha k+1\right)}+ \\
& +\frac{\left(8 \beta k^{2}+5 \alpha k+2\right) z^{3}}{36 k^{2}\left(13 \beta k^{2}+4 \alpha k+1\right)\left(7 \beta k^{2}+3 \alpha k+1\right)^{2}}- \\
& -\frac{\left(210 \beta^{2} k^{4}+170 \alpha \beta k^{3}+50 \alpha^{2} k^{2}+49 \beta k^{2}+36 \alpha k+7\right) z^{4}}{324 k^{3}\left(21 \beta k^{2}+5 \alpha k+1\right)\left(13 \beta k^{2}+4 \alpha k+1\right)\left(7 \beta k^{2}+3 \alpha k+1\right)^{3}}+\ldots
\end{aligned}
$$

As before, calculate the coefficients of the continued fraction corresponding to the series (42) by formulas (10) and write expressions for the sequence of $B_{n}(13)$ :

$$
\begin{aligned}
B_{1}= & \frac{1}{6 k\left(7 \beta k^{2}+3 \alpha k+1\right)}, \\
B_{2}= & \frac{-5 \beta k^{2}+\alpha k+1}{36 k^{2}\left(13 \beta k^{2}+4 \alpha k+1\right)\left(7 \beta k^{2}+3 \alpha k+1\right)^{2}}, \\
B_{3}= & \frac{1}{648 k^{3}\left(21 \beta k^{2}+5 \alpha k+1\right)\left(13 \beta k^{2}+4 \alpha k+1\right)^{2}\left(7 \beta k^{2}+3 \alpha k+1\right)^{3}} \times \\
& \times\left(1428 \beta^{3} k^{6}+100 \alpha \beta^{2} k^{5}-115 \alpha^{2} \beta k^{4}+25 \alpha^{3} k^{3}-514 \beta^{2} k^{4}-\right. \\
& \left.\quad-312 \alpha \beta k^{3}+13 \alpha^{2} k^{2}-68 \beta k^{2}+8 \alpha k+2\right),
\end{aligned}
$$

(c) А.И. Землянухин, А.В. Бочкарёв

Изв. вузов «ПНД», т. 24, № 4, 2016 
In accordance with (36) the first fraction of the sequence of convergents (11) which can match the solution with the 1 st order pole is $P_{2} / Q_{2}$ (Pade approximant [1/1]). In order to continued fraction corresponding the series (42) terminates and coincide with $P_{2} / Q_{2}$, it is necessary that all the values (43) starting from $B_{2}$ go to zero. From the condition $B_{2}=0$ we find

$$
\alpha=\frac{5 \beta k^{2}-1}{k} .
$$

Substituting (44) into (43), we have

$$
\begin{aligned}
& B_{1}=\frac{1}{12 k\left(11 \beta k^{2}-1\right)} \\
& B_{2}=0, \\
& B_{3}=\frac{\beta k^{2}-1}{5184 k^{3}\left(23 \beta k^{2}-2\right)\left(11 \beta k^{2}-1\right)},
\end{aligned}
$$

As it is seen, only one condition (44) is not enough. Demanding $B_{3}=0$, obtain the second condition

$$
\beta=\frac{1}{k^{2}} \text {. }
$$

Pair of conditions (44), (45) is enough to the continued fraction terminates and matches up with a convergent $P_{2} / Q_{2}$, which in this case takes the form

$$
v=\frac{P_{2}}{Q_{2}}=[1 / 1]=\frac{120 z k}{z+120 k} .
$$

Substituting the expression obtained for $v$ in (41), we find $u$ as follows

$$
u=\frac{120^{3} k^{3} z}{(z+120 k)^{3}} .
$$

Replacing $z$ in (46) by expression (5) and taking into account the dispersion relation (39) and the conditions (44), (45) for the coefficients of the equation KS, we get the exact solution

$$
u=\frac{120^{3} k^{3} \varepsilon \exp \left(k x-6 k^{2} t\right)}{\left[\varepsilon \exp \left(k x-6 k^{2} t\right)+120 k\right]^{3}} .
$$

The solution (47) can be obtained in the other way. For example, the replacement of the dependent variable $u=w^{3}$ transforms (37) to equation, the solution of which has the pole of the 1st order. Substitution $u=w_{x}$ in (37) allows to decrease the order of solution pole by one. In both cases the application of the proposed method to the transformed equations enabled us to obtain the solution (47), but with increased computational costs.

\section{Scheme of the method. Advantages and disadvantages}

The examples above allow us to represent a general scheme of the method of finding the exact solitary-wave solutions to evolution equations.

Step 1. Preparation of the perturbation series in the form of a power series based on the solution of the linearized problem. 
Step 2. Calculation of sequence $B_{n}$ of products of the coefficients of the continued fraction corresponding to the perturbation series.

Step $3 a$. For an integrable equation, there exists a natural number $r$, such that

$$
\forall n \geq r \Rightarrow B \equiv 0,
$$

the continued fraction terminates unconditionally and is transformed into the convergent $P_{r} / Q_{r}$. The perturbation series is geometric and the fraction $P_{r} / Q_{r}$ gives an expression for the sum of the series and the exact solution to the equation.

Step $3 b$. For non-integrable equation the solutions of which have a pole of order $q$, it is necessary to find conditions under which for some natural $r \geq 2 q$ the inequality (48) is true. Such conditions, if found, establish the connection between coefficients of the equation and the parameters of its solution. When these conditions are met the perturbation series becomes geometric, the continued fraction is transformed into a convergent $P_{r} / Q_{r}$ and gives the exact solution to the equation. If such conditions could not be found, the equation can be solved by this method.

In practice, the equality to zero of three or four successive quantities $B_{n}$ in step $3 \mathrm{~b}$ indicates the condition (48) is met and the exact solution is found, that can be checked by substitution of the appropriate convergent $P_{r} / Q_{r}$ into the original equation.

The advantages of the method include the ability to work with equations, the solution of which has a pole of zero, fractional, or high natural order. In these cases, the perturbation series should be transformed so that it matches a function with a pole of the first or second order. For this the perturbation series can be term-by-term differentiated, raised to a rational degree, inversed and so on.

The steps of the method are easy to automate with any of the modern systems of symbol mathematics.

The method can be used as an empirical criterion of integrability of evolutionary equations: if the perturbation series is geometric or becomes such under the condition including only the coefficients of the equation, the equation with high probability relates to integrable. After checking most of integrable evolution equations contained in [13], we have not found any counterexample. Note that geometricity of the series under condition that includes both the coefficients of the equation and the solution parameters, such as (44) and (45), indicates that the equation is non-integrable.

The disadvantages of the method include inability to classify all exact solutions of evolution equations and impossibility of solving equations with variable coefficients.

This research was supported by RFBR (project No. 16-01-00176-a).

\section{References}

1. Hirota R. Exact solution of the Korteweg-de Vries equation for multiple collisions of solitons // Phys. Rev. Lett. 1971. Vol. 27. Pp. 1192-1194.

2. Baker G.A.Jr., Graves-Morris P. Padé Approximants, Cambridge: Cambridge U.P., 1996.

3. Manevitch L.I. Linear and nonlinear mathematical physics: from harmonic waves to solitons // Soros. Obrazov. Journ. 1996. N1. Pp. 86-93 (Russian).

4. Jones W.B., Thron W.J. Continued fractions: analytic theory and applications. Reading, MA: Addison-Wesley, 1980.

(c) А.И. Землянухин, А.В. Бочкарёв

Изв. вузов «ПНД», т. 24, № 4, 2016 
5. Zemlyanukhin A.I., Bochkarev A.V. The perturbation method and exact solutions of nonlinear dynamics equations for media with microstructure // Computational Continuum Mechanics. 2016. Vol. 9, N2. Pp. 182-191 (Russian).

6. Lambert F. and Musette M. Solitary waves, padeons and solitons // Lect. Notes Math. 1984. Vol. 1071. Pp. 197-212.

7. Lambert F., Musette M. Solitons from a direct point of view: padeons // J. Comp. Appl. Math. 1986. Vol. 15. Pp. 235-249.

8. Baikov V.A., Khusnutdinova K.R. Formal linearization and exact solutions of some nonlinear partial differential equations // J. Nonlin. Math. Phys. 1996. N3. Pp. 139-146.

9. Bender C.M., Milton K.A. Continued fraction as a discrete nonlinear transform // J. Math. Phys. 1994. Vol. 35, N1. Pp. 364-367.

10. Cohen H. Numerical Approximation Methods. New York: Springer-Verlag, 2011.

11. Khovansky A.N. Applications of continued fractions and their generalization to problems in approximation theory. Groningen: P. Noordhoff N.V., 1963.

12. Meshkov A.G., Sokolov V.V. Integrable evolution equations with the constant separant // Ufa Math. J. 2012. Vol. 4, N3. Pp. 104-153.

13. Encyclopedia of Integrable Systems / A.B. Shabat, V.E. Adler, V.G. Marikhin, V.V. Sokolov (Eds.), L.D. Landau Institute for Theoretical Physics - Research Institute for Symbolic Computations, J. Kepler Universität, 2007.

14. Gandarias M.L., Saez S. Traveling-wave solutions of the Calogero-DegasperisFokas equation in 2+1 dimensions // Theor. Math. Phys. 2005. Vol. 144, N1. Pp. $916-$ 926.

15. Ryabov P.N. Exact solutions of the Kudryashov-Sinelshchikov equation // Appl. Math. Comput. 2010. Vol. 217, N7. Pp. 3585-3590.

16. The Painlev' Property: One Century Later / R. Conte (Ed.). New York: Springer, 1999.

17. Kudryashov N.A. Methods of nonlinear mathematical physics. Dolgoprudnyj: Izd. Dom Intellekt, 2010.

\title{
НЕПРЕРЫВНЫЕ ДРОБИ, МЕТОД ВОЗМУЩЕНИЙ И ТОЧНЫЕ РЕШЕНИЯ НЕЛИНЕЙНЫХ ЭВОЛЮЦИОННЫХ УРАВНЕНИЙ
}

\author{
А. И. Землянухин, А. В. Бочкарёв \\ Саратовский государственный технический университет имени Гагарина Ю. А. \\ 410054 Саратов, ул. Политехническая, 77 \\ E-mail: zemlyanukhinai@sstu.ru
}

\begin{abstract}
Предложен новый метод построения точных решений нелинейных эволюционных уравнений, основанный на последовательном применении метода возмущений и аппарата непрерывных дробей. Показано, что точные уединенно-волновые решения возникают в предельном случае как суммы геометрических рядов метода возмущений на основе
\end{abstract}


линеаризованной задачи. Продемонстрировано, что непрерывная дробь, соответствующая ряду возмущений, обрывается, и оставшаяся подходящая дробь дает выражение для искомого точного солитоноподобного решения. Установлено, что порядок подходящей дроби не меньше удвоенного порядка полюса решения исходного уравнения. Эффективность метода продемонстрирована на решении интегрируемых уравнений: семейства Кортевега-де Вриза 5-го порядка, третьего порядка с 5-ю произвольными постоянными, Калоджеро-Дегаспериса-Фокаса и неинтегрируемого уравнения КурамотоСивашинского. Проведенный анализ показал, что в случае интегрируемых уравнений непрерывная дробь, соответствующая степенному ряду метода возмущений, обрывается безусловно, то есть ряд является геометрическим или становится таковым после перегруппировки слагаемых. Для неинтегрируемых уравнений требование обрывания непрерывной дроби, равносильное геометричности ряда метода возмущений, приводит к условиям на коэффициенты исходного уравнения, необходимым для существования точных солитоноподобных решений. К преимуществам метода, который может быть легко реализован с помощью любой из систем компьютерной математики, можно отнести возможность работы с уравнениями, решение которых имеет полюс нулевого, дробного или высокого натурального порядка.

Ключевые слова: Непрерывные дроби, метод возмущений, точные решения, нелинейные эволюционные уравнения.

DOI: $10.18500 / 0869-6632-2016-24-4-71-85$

Ссылка на статью: Землянухин А.И., Бочкарев А.В. Непрерывные дроби, метод возмущений и точное решение нелинейных эволюционных уравнений // Известия вузов. Прикладная нелинейная динамика, 2016. Т. 24. № 4. Р. 71-85.
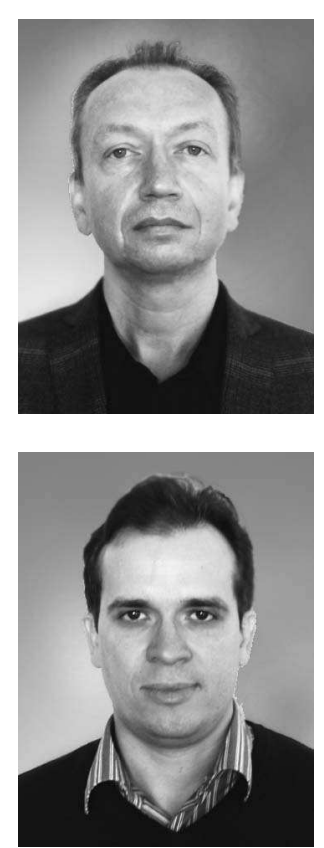

Землянухин Александр Исаевич родился в 1967 году в Саратове, окончил с отличием механико-математический факультет Саратовского государственного университета в 1989 году. Заведующий кафедрой «Прикладная математика и системный анализ» Саратовского государственного технического университета. Защитил диссертации на соискание учёной степени кандидата физикоматематических наук в СГУ (1995) и доктора физико-математических наук в Институте проблем машиноведения РАН (1999) в области динамических задач механики деформируемого твердого тела. Автор монографии «Нелинейные волны в цилиндрических оболочках: солитоны симметрии, эволюция» (1999, в соавторстве с Л.И.Могилевичем). Области научных интересов: нелинейная волновая динамика деформируемых систем, аналитические и численные методы нелинейной математической физики.

410008 Саратов, Политехническая, 77

Саратовский государственный технический университет имени Гагарина Ю.А.

E-mail: zemlyanukhinai@sstu.ru

Бочкарёв Андрей Владимирович родился в 1973 году в Саратове, окончил с отличием физический факультет Саратовского государственного университета в 1995 году. Доцент кафедры «Прикладная математика и системный анализ» Саратовского государственного технического университета. Защитил диссертацию на соискание учёной степени кандидата технических наук в СГТУ (1999). Научные интересы: нелинейная волновая динамика деформируемых систем, точные решения нелинейных уравнений в частных производных.

410008 Саратов, Политехническая, 77

Саратовский государственный технический университет имени Гагарина Ю.А.

E-mail: ab2009sar@list.ru

(C) А.И. Землянухин, А.В. Бочкарёв

Изв. вузов «ПНД», т. 24, № 4, 2016 